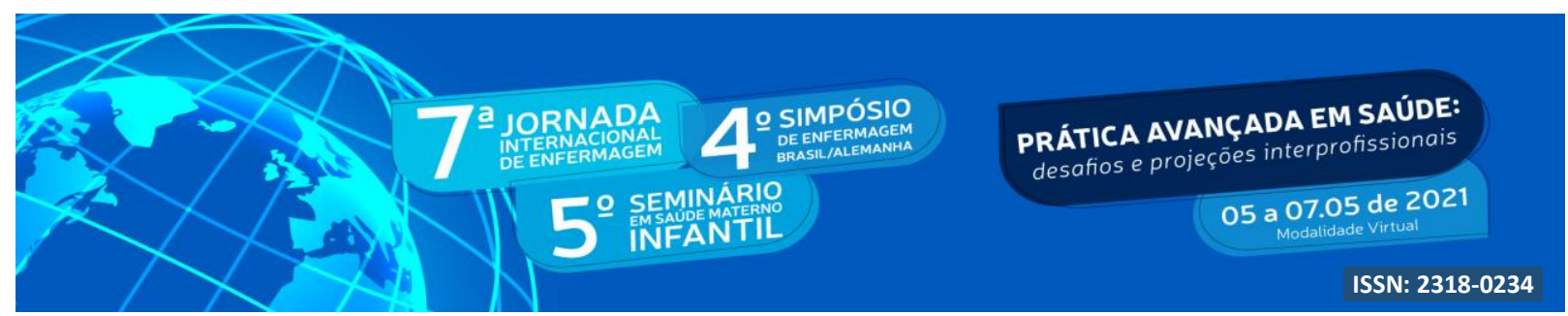

DOI: http://doi.org/10.48195/jie2021-018

\title{
SAÚDE DA POPULAÇÃO TRANSGÊNERO: ANÁLISE TEÓRICO-REFLEXIVA À LUZ DO PENSAMENTO DA COMPLEXIDADE ${ }^{1}$
}

\section{Êmilly Barcelos Petter²; Julia de Oliveira Machado²; Juliane Damasceno²; Regina Célia de Castro Gomes ${ }^{3}$; Dirce Stein Backes ${ }^{4}$}

\begin{abstract}
RESUMO
Este trabalho teve por objetivo refletir e intervir em relação às fragilidades evidenciadas em serviços de saúde associados à falta de acolhimento, preconceito, discriminação e capacitação dos profissionais do Sistema Único de Saúde (SUS), no que se refere ao atendimento da população LGBTQIA+, em especial de transgêneros. Trata-se de uma análise teórico-reflexiva, desenvolvida a partir de um caso fictício fundamentado na Sistematização de Assistência de Enfermagem e no referencial da Teoria da Complexidade de Edgar Morin, como atividade avaliada na disciplina de Fundamentos Teórico Filosóficos da Enfermagem do curso de Enfermagem. O estudo trouxe à luz preconceitos vivenciados pela população LGBTI+, possibilitou o repensar de atitudes e posturas profissionais e sinalizou, acima de tudo, para à necessidade de prospectar políticas de saúde coerentes e condizentes com as reais necessidades de promoção e educação da saúde desta população, com autonomia e respeito.
\end{abstract}

Palavras-chave: Enfermagem; Pessoas Transgêneros; Processo de Enfermagem.

\begin{abstract}
This study aimed to reflect and intervene in relation to the weaknesses evidenced in health services associated with the lack of welcoming, prejudice, discrimination and training of professionals in the Unified Health System (SUS), with regard to the care of the LGBTQIA + population, in special for transgender people. This is a theoretical-reflective analysis, developed from a fictitious case based on the Systematization of Nursing Assistance and on the framework of Edgar Morin's Theory of Complexity, as an activity evaluated in the discipline of Theoretical Philosophical Foundations of Nursing in the Nursing course. The study brought to light the prejudices experienced by the LGBTI + population, made it possible to rethink professional attitudes and attitudes and signaled, above all, the need to prospect coherent health policies consistent with the real needs of health promotion and education of this population, with autonomy and respect for yours.
\end{abstract}

Key Words: Nursing; Nursing Process; Transgender Persons.

\footnotetext{
${ }^{1}$ Trabalho relacionado à disciplina de Fundamentos Teóricos Filosóficos da Enfermagem do Curso de Enfermagem da Universidade Franciscana - UFN.

${ }^{2}$ Acadêmicas do Curso de Enfermagem da Universidade Franciscana - UFN. E-mail: emillypetter@gmail.com juliam.jornal@gmail.com judamasceno.89@gmail.com

${ }^{3}$ Enfermeira. Aluna do Mestrado Profissional em Saúde Materno Infantil da Universidade Franciscana - UFN. E-mail: regina.castro@ufn.edu.br

${ }^{4}$ Orientadora. Doutora em Enfermagem. Professora do Curso de Enfermagem da Universidade Franciscana UFN. E-mail: backesdirce@ufn.edu.br
} 


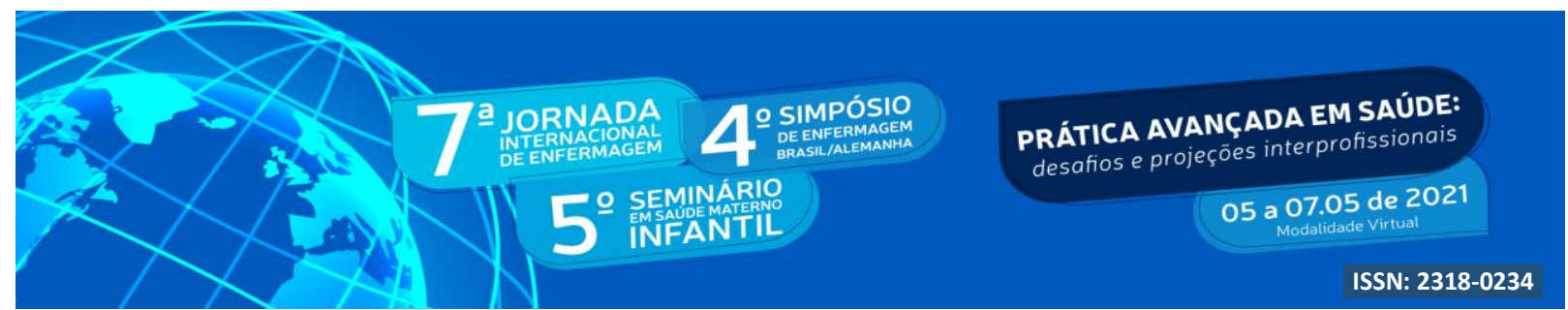

\section{INTRODUÇÃ̃O}

Os dados da Associação Nacional de Travestis e Transexuais (ANTRA) são notórios e denotam a necessidade de avanços. O Brasil é o país que mais assassina transexuais no mundo inteiro. Em 2019 foram 124 casos de homicídio motivados por transfobia. Isso tudo, sem contar os dados de agressão sem o homicídio consumado e as subnotificações das ocorrências (ANTRA, 2019). A visibilidade das causas transexuais tem crescido exponencialmente, no entanto, o ciclo de violência não é cessado de forma tão rápida. Discutir questões relacionadas às demandas sociais, assim como, a violência, discriminação e marginalização que sofrem, inclui pensar políticas de saúde para a comunidade Lésbicas, Gays, Bissexuais, Travestis, Transexuais e Intersexo (LGBTTI), já que, parte das ações violentas acontecem nos serviços de saúde (BENTO; PELÚCIO, 2012; SOUZA, 2015;).

A investigação a partir do contexto das políticas do Sistema Único de Saúde (SUS) voltadas ao processo transsexualizador, de promoção de saúde, prevenção e tratamento de doenças é a principal base que direcionará esta pesquisa. Compreender as tensões, impasses e precariedades nas políticas públicas e na atuação dos profissionais, possibilitará para além de entender a hierarquização dos grupos sociais, verificar e legitimar a importância da qualificação profissional e da humanização do atendimento dentro dos serviços de saúde. Partindo dessa premissa, considera-se a Sistematização de Assistência da Enfermagem (SAE) importante ferramenta para que se estabeleça um atendimento efetivo e de qualidade dentro do sistema de saúde. Implementar a SAE significa realizar uma avaliação aprofundada, baseada na ciência, mas também no contexto sensível, individual e particular de cada indivíduo (COFEN, 2009). Pensar a SAE como um processo sistêmico, prospectivo e indutor de um novo pensar e agir, levou-nos ao questionamento: Como oportunizar um acompanhamento de qualidade à população LGBT0+I nos serviços do SUS, desprovidos de preconceitos e alienações?

A proposta de trabalho tange um processo de implementação com fins formativos e educacionais. Assim, será desenvolvido um material visual que traz alguns pontos importantes no que diz respeito ao atendimento humanizado da população transgênero dentro do sistema de saúde. O público alvo deste material, assim como da reflexão proposta neste trabalho, são 


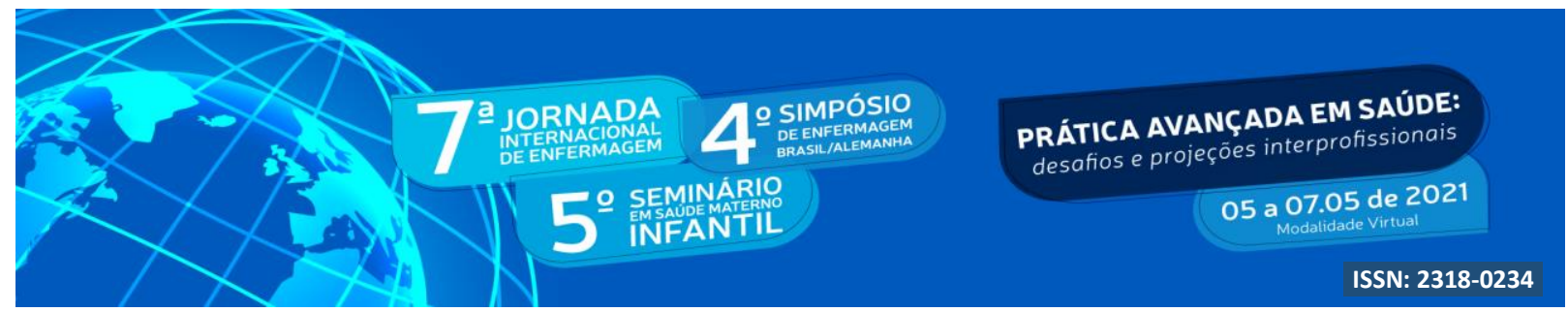

principalmente os estudantes e profissionais da área de saúde, tendo em vista a necessidade de um atendimento digno, humanizado e qualificado.

Sob esse enfoque, o presente estudo se justifica por inúmeros motivos. Dentre eles, a relevância social que os temas relacionados a comunidade LGBTI+ diante de um momento histórico repleto de discussões arrolado ao preconceito velado, enraizado por séculos de conservadorismo e perpetuado por uma sociedade patriarcal. Os profissionais da saúde são parte essencial na quebra de padrões/modelos de relação e atendimento da população transgênero dentro de um sistema opressor.

\section{OBJETIVO}

Objetiva-se refletir e intervir, por meio de um infográfico, em relação às fragilidades evidenciadas em serviços de saúde asossicadas à falta de acolhimento, preconceito, discriminação e capacitação dos profissionais do Sistema Ùnico de Saúde (SUS), no que se refere ao atendiemnto da população LGBTI+.

\section{METODOLOGIA}

Trata-se de uma análise teórico-reflexiva, desenvolvida a partir de um caso fictício embasado na entrevista realizada no documentário "Maria e Luísas" de Oliveira et al. 2020, fundamentado na Sistematização de Assistência de Enfermagem e no referencial da Teoria da Complexidade de Edgar Morin, como atividade avaliativa para a disciplina de Fundamentos Teórico Filosóficos da Enfermagem do curso de Enfermafem, no segundo semestre de 2020.

A Sistematização de Assistência de Enfermagem (SAE), se organiza, em cinco etapas, quais sejam: histórico de enfermagem, diagnóstico, planejamento, implementação e avaliação (COFEN, 2009). Com base em informações que presumem a relevância da discussão, engloba a problemática na dinâmica de ofertas e demandas de serviços de saúde do SUS para a população transgêneros.

O pensamento da complexidade, proposto por Edgar Morin, provoca o repensar de atitudes e posturas profissionais. O autor sustenta, portanto, que não basta rever doutrianas, métodos e intervenções, mas induz ao pensar uma nova concepção do próprio conhecimento. Uma concepção ampliada do pensar, capaz de transcender a simplificação, a fragmentação de saberes e, sobretudo, a questionar os reducionismos relacionados às exclusões de pessoas, 


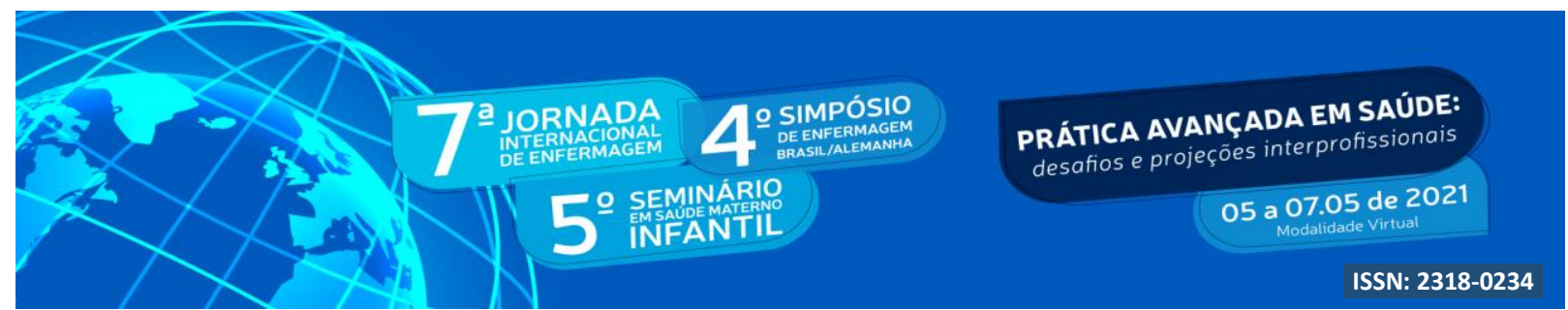

classes e condições sociais (MORIN, 2010, 2021).

A composição sucedeu-se atrelada a subsídios teóricos que permeiam cartilhas e cadernos do Ministério da Saúde, com abordagens voltadas às temáticas de transgêneros. Mais especificamente às questões de desigualdade, poder, hierarquia social, marginalização, dentre outros. Em relação aos diagnósticos explanados, estes sucederam-se a partir do pensamento complexo de Edgar Morin, em que, em suma, considera todos campos de conhecimentos como válidos, capazes de ampliar a compreensão do próprio sujeito, dos contextos, relações, realidade, entre outros.

Elaborou-se, a partir de processos reflexivos, um infográfico que possa auxiliar e induzir melhorias no cuidado em saúde da população LGBTI+, em especial, de transgêneros. O material vai ser disponibilizado nas Unidades Básicas de Saúde e espaços de circulação dos estudantes dos cursos da saúde.

\section{RESULTADOS E DISCUSSÃO}

Neste item será detalhado um caso fictício, organizado com base nos passos metodológicos da SAE, quais sejam: Histórico, Diagnóstico, Planejamento e Implementação e analisados à luz da teoria de Edgar Morin. Não realizadas, apenas, a fase de avaliação, em funlão do período de estudo.

\subsection{Histórico de Enfermagem}

Elis Miranda (nome social), 34 anos, mulher transgênero, nascida em uma capital brasileira. Solteira. Trabalha como acompanhante e garota de programa no centro da cidade. Faz uso de hormonização (estrogênio) por conta própria desde a adolescência. Não sabe mencionar ao certo a dose utilizada semanalmente. Tem o ensino fundamental incompleto. Procurou o consultório na rua. Sua queixa principal é o aparecimento recente de algumas manchas nas palmas das mãos e nas plantas dos pés. Não relata coceira ou dor. Teve episódios de febre, dor de cabeça e mal-estar nos últimos 10 dias. Recorda que a cerca de dois meses observou a presença de uma ferida na boca, cicatrizada posteriormente.

Ao ser questionada sobre estar vinculada a alguma UBS, ou fazer algum acompanhamento, a mesma relata que não. Recorda que há oito anos procurou uma unidade pois precisava dar pontos em um corte profundo na cabeça, que sofrera por conta de uma 


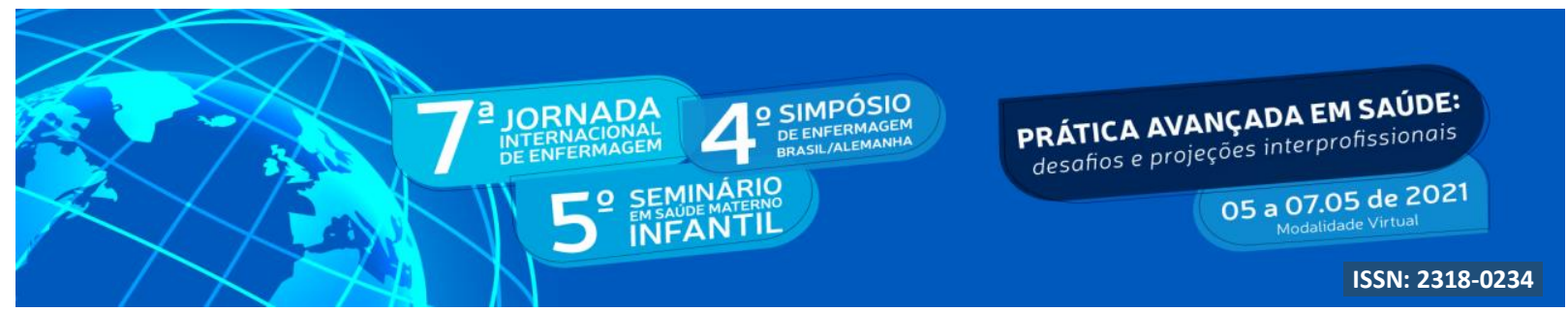

agressão. Relata ter sofrido muito constrangimento nesse ambiente. Os funcionários a chamaram pelo nome de registro, e se recusaram a usar seu nome social. Se sente oprimida e constrangida ao ter que procurar o Sistema de Saúde.

Atualmente divide uma casa com mais duas travestis. Faz programas para conseguir se sustentar. Desde que saiu de casa, aos 12 anos, não retomou os estudos. Expressa desde muito jovem seu amor por maquiagens, vestidos e sapatos que eram de sua mãe. Mesmo que sem muitos recursos, sempre admirou o universo feminino, o ser feminino e se identificou como mulher. Sua mãe é faxineira e seu pai vigia noturno. Quando jovem seus pais trabalhava muito, e Elis ficava aos cuidados de sua tia, irmã de sua mãe. Relembra com sofrimento o abuso sofrido pelo tio até seus sete anos de idade. Aos 12 fugiu de casa e foi viver na rua. Desde então, nunca teve contato com a família. Sua rede de apoio atual conta com algumas amigas, as quais dividem o teto.

Desde que mora na rua lembra-se de sofrer abusos e violências diversas. Em relação à transição de gênero, além da hormonização, refere o sonho de colocar próteses de silicone nos seios e de realizar cirurgia de mudança de gênero, mas que para a mesma é um sonho distante. Que se sente incompleta e triste com a situação. Pois pelo SUS é difícil de pagar e envolve recursos financeiros a qual não possui. Em sua estada na rua fez uso abusivo de álcool e outras drogas. Maconha e cocaína. Atualmente relata faz uso de bebida alcoólica regularmente. Realizado teste rápido para testagem de sífilis e HIV. Positivo para sífilis.

\subsection{Diagnósticos de Enfermagem à luz do pensamento da complexidade de Edgar Morin}

Olhar, mesmo que atentamente, em um único ponto, nos faz mergulhar em profundidade, mas não possibilita que este olhar seja estendido sob o tecido de acontecimentos, interações e transformações do universo em sua plenitude (MORIN, 2011).

Compreender um fenômeno é dar espaço para a sinergia de componentes heterogêneos e indissociáveis de cada evento. E quando falamos sobre o cuidado realizado por profissionais da área da saúde, não é diferente. Para que um diagnóstico de enfermagem seja realizado de forma eficiente, cada um dos nós e laços que compõem o universo do paciente/usuário devem ser valorizados. O poder do cuidado está atrelado à amplitude deste notar. Com base nisso, os diagnósticos realizados a partir do "Histórico de Enfermagem"e no contexto deste trabalho, foram fundamentados na perspectiva sistêmica e no pensamento complexo de Morin. 


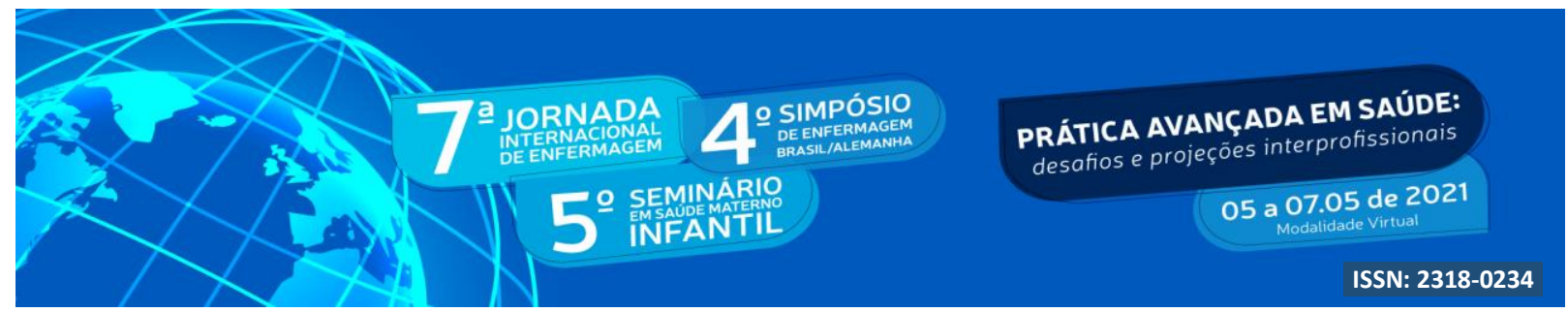

O preconceito é uma das peças principais do alicerce dos múltiplos discursos de ódio da atualidade. Baseado na moral, na religião ou, até mesmo na ciência, o preconceito naturaliza determinadas práticas sociais e influencia na legitimidade de direitos de determinados atores e grupos. De acordo com Prado e Machado (2008) o preconceito faz com que não consigamos identificar os limites a partir da percepção da realidade, e acaba por justificar inferiorizações através de seus mecanismos.

O último boletim (1 de janeiro a 31 de outubro de 2020) de assassinatos contra travestis e transexuais brasileiras disponibilizado pela ANTRA trouxeram dados alarmantes. O número de assassinatos motivados por ódio cresceu cerca $48 \%$ em relação ao ano passado. A cada três dias um transgênero é assassinado violentamente motivado por preconceito no país. Além disso, os dados fornecidos pela Associação colocam pelo décimo segundo ano consecutivo, o Brasil como o país que mais violenta e assassina transgêneros no mundo. No quesito segurança para a população trans caímos para $68^{\circ}$ lugar (ANTRA, 2020).

Com base nos números, e nos tantos relatos públicos de transgêneros, podemos mensurar um pouco da realidade hostil, violenta e desumana que a maior parcela da população trans enfrenta diariamente em sua busca por legitimidade de direitos. As concepções ideologicas de inferiorização social e de patologização da comunidade LGBTI+ ficam mais do que evidentes. Para Prado e Machado (2008) quanto mais uma realidade se distancia da cultura heteronormativa, mais assume o status de perversão, pecado, doença, degenração e anomalia.

A transfobia dentro de ambientes que prestam serviços de saúde, limitam o acesso ao cuidado com a saúde de forma geral, e aos serviços específicos para a comunidade dentro do SUS. Essas limitações resultam na adoção de caminhos alternativos, não seguros, dentro dos seus grupos, onde são realizados os procedimentos para obter as mudanças físicas corporais desejadas, Ferreira et al. (2017), apontam que essas mudanças no corpo, ocorrem numa perspectiva solitária, clandestina, invisível ao estado e logo ao SUS. Estes sujeitos que por não serem reconhecidos ou tratados como clientelas legítimas dos serviços de saúde, ficam expostos constantemente ao risco de morte.

A violência e o preconceito nos espaços de saúde são expressamente vivenciadas pelas travestis, que nesse sentido experienciam a falta de acolhimento pelos profissionais de saúde, da não observância das especificidades, com desconhecimento das iniciativas governamentais, na promoção da equidade e respeito a diversidade dos usuários. Rocon et al. (2016) 


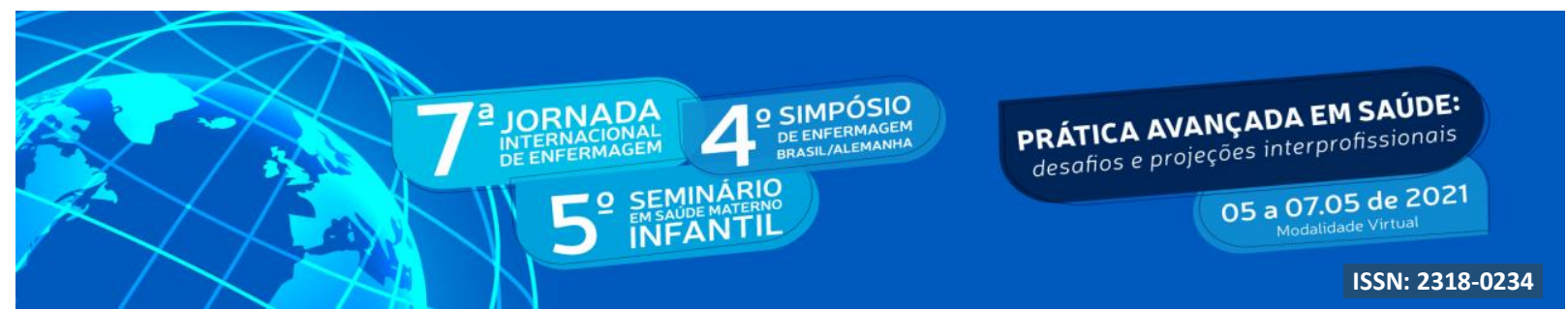

exemplificam a discriminação com base no desrespeito ao nome social nos serviços de saúde, e Souza et al (2015) destacam as situações de violência por meio de "chacota"e, humilhação, discriminação, entre outras situações, o que leva a evitar adentrar os equipamentos e serviços de saúde, o que reflete na piora de suas condições de saúde (ROCON et al., 2020).

Como maneira de romper as barreiras que permeiam o acesso aos serviços de saúde e orientar os profissionais de saúde e legitimar a assistência aos usuários LGBTTI, se deu a implantação da Política Nacional de Saúde Integral de Lésbicas, Gays, Bissexuais, Travestis e Transsexuais. Seu direcionamento, reconhece identidade de gênero como determinante social no processo saúde/doença e propõe, a partir daí, estratégias de melhoria nas condições da saúde deste grupo, a redução das desigualdades e iniquidades no acesso às condições de moradia, trabalho, educação, lazer e saúde (BRASIL, 2013).

Em consonância a Paim (2009), ao falar sobre o Sistema de Saúde, aborda a promoção, proteção e recuperação da saúde como uns dos principais norteadores para uma ação integral, as quais, em síntese, significa cultivar e estimular por medidas gerais e inespecíficas a saúde e a qualidade de vida das pessoas e da comunidade, levando em viés as condições de vida, educação, lazer, alimentação, cultura, entre outros. Além de reduzir ou eliminar riscos e um tratamento oportuno.

\subsection{Planejamento e Implementação de Enfermagem}

A teoria da complexidade prevê na formação profissional um constante processo de reflexão-ação-reflexão, e isso sugere uma constante construção, desconstrução, reconstrução do fazer/pensar capaz de contribuir para a inovação das práticas profissionais como ciência e disciplina (FALCON et al., 2006). Nesse sentido, para que o cuidado de enfermagem encontre respaldo na prática em saúde, na ótica da complexidade, há que se considerar a interdisciplinaridade nas ações, sendo indispensável a promoção de olhares múltiplos e abrangentes para o favorecimento de um cuidado integral, que seja capaz de compreender a complexa realidade dos sistemas de cuidado em saúde e as necessidades impostas por panoramas construídos pela diversidade terapêutica (MENOSSI, 2004).

Dessa forma, a sistematização da assistência de enfermagem se apresenta como uma importante ferramenta para melhoria dos processos de cuidados, compreendendo uma prática de gestão de enfermagem que pode levar à auto-organização nos serviços de saúde. A prática 


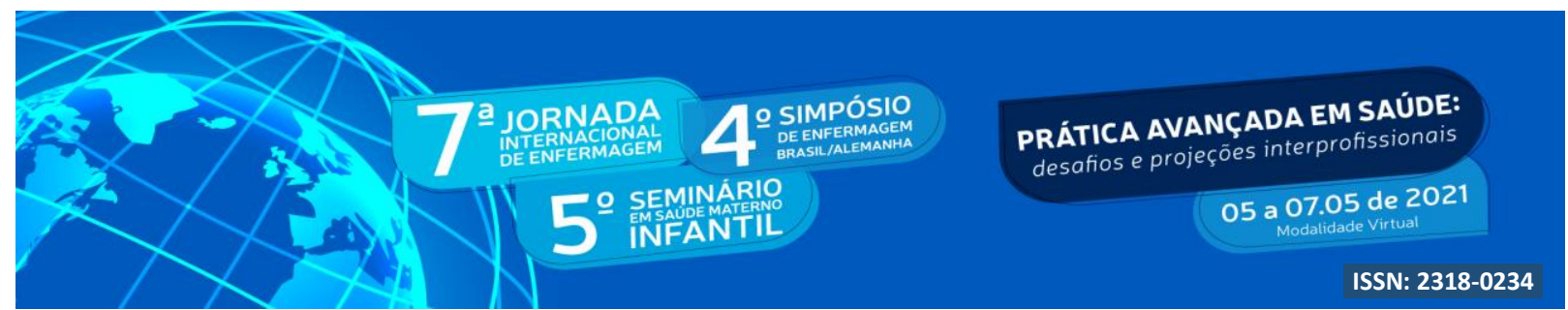

da enfermagem organizada e sistematizada tem sido uma das principais buscas dos 8 enfermeiros em prol do saber científico da profissão e da melhoria da qualidade do cuidado prestado.

Para Morin (2003, p.51)

A compreensão humana nos chega quando sentimos e concebemos os humanos como sujeitos; ela nos torna abertos a seus sofrimentos e suas alegrias. permite-nos reconhecer no outro os mecanismos egocêntricos de autojustificação, que estão entre nós, bem como as retroações positivas (no sentido cibernético do termo) que fazem degenerar em conflitos inexplicáveis as menores querelas. É a partir da compreensãoque se pode lutar contra o ódio e a exclusão.

Elaborou-se, com base na problemática levantada e amplamente discutida, um planejamenro de intervenções, de cunho informativo-educativo, por meio de material visual, do tipo infográfico educativo (Figura 1). Intentou-se, com base nesta abordagem, a orientar e instigar os profissionais de saúde, sobre questões pertinentes e imprescindíveis no que tange a atenção em saúde da população LGBTI+.

Figura 1: Infográfico produzido a partir de algumas questões pertinentes do trabalho.

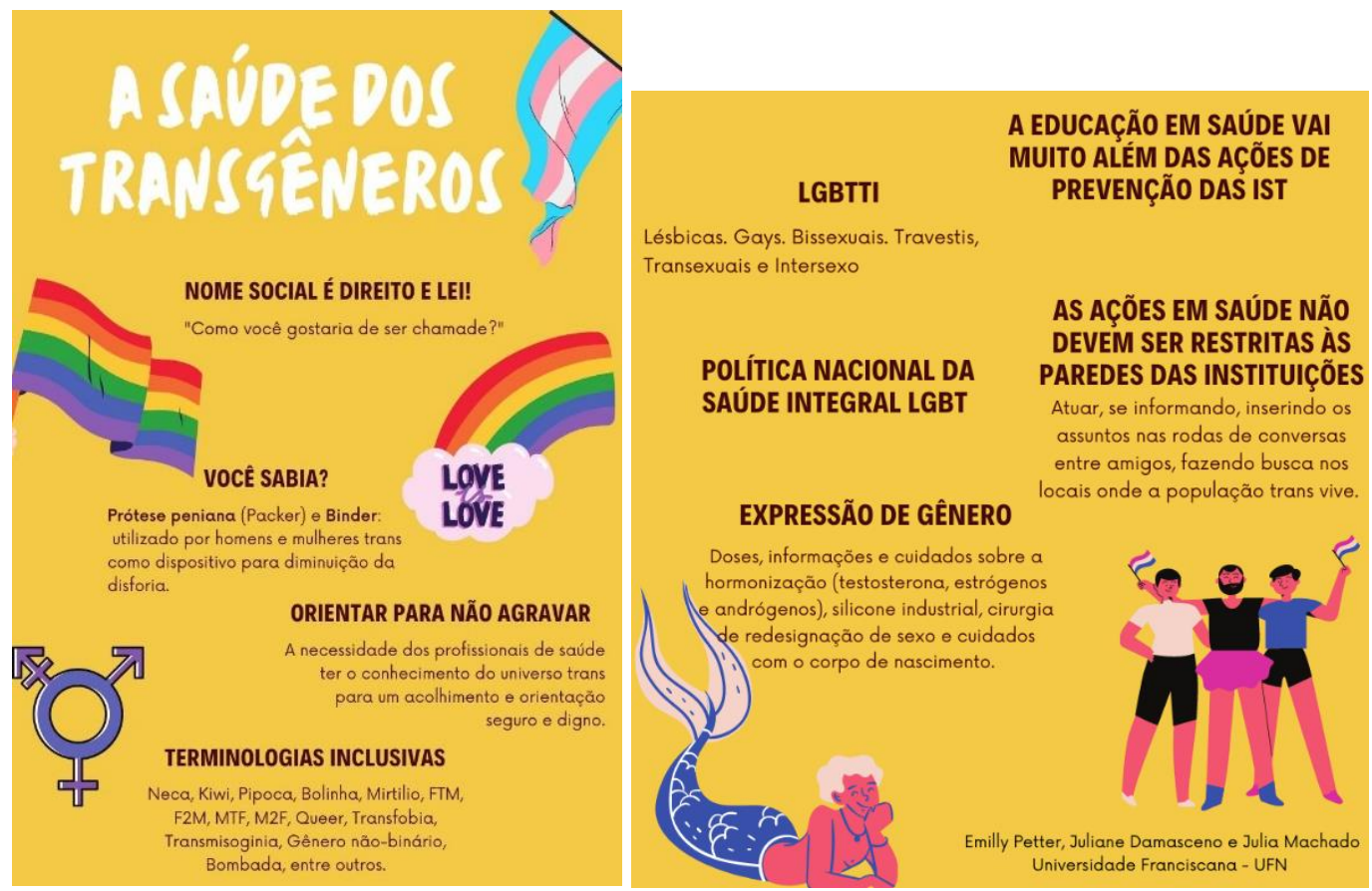




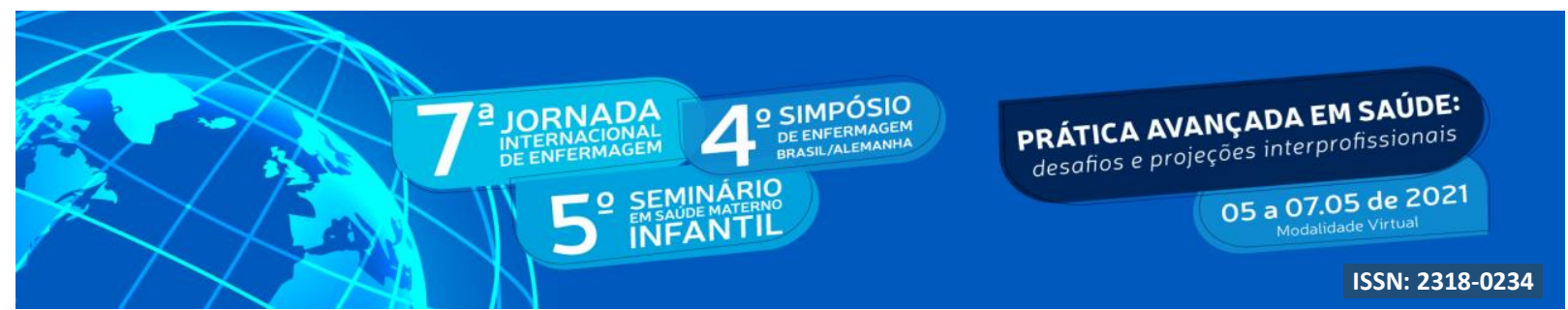

\section{CONCLUSÃO}

O estudo trouxe à luz preconceitos vivenciados pela população LGBTI+, possibilitou o repensar de atitudes e posturas profissionais e sinalizou, acima de tudo, para à necessidade de prospectar políticas de saúde coerentes e condizentes com as reais necessidades de promoção e educação da saúde desta população, com autonomia e respeito.

Com base no objetivo proposto foi possível concluir que a população transgênero sofre constantemente ataques aos seus direitos constitucionalmente previstos. O sistema de saúde descumpre seu compromisso a partir de seus princípios e diretrizes quando seus profissionais atuam de forma desumana, antiética e despreparada, reforçando estigmas que resultam ainda mais na invisibilidade desses sujeitos, enquanto cidadãos e humanos.

Consideram-se questões do contexto social como violência, preconceito, são determinantes no processo saúde/doença dos sujeitos. Logo, acolher as demandas de forma humanizada, considerar as singularidades do usuário, as trajetórias de vida se tornam essenciais no cuidado as pessoas. Ações essas, que convergem aos princípios que norteiam o SUS, promovendo acesso aos serviços de saúde de forma universal, equânime.

O modo como se concretiza o cuidado, as relações, as trocas, inclusive na assistência em saúde, direcionam ou não, para quebrar a rede de preconceito e violência, as quais a população trans é submetida diariamente, nos diversos ambientes sociais. O respeito a vida, ao ser humano, as particularidades de cada sujeito, sempre é o melhor modo de cuidar do outro.

\section{REFERÊNCIAS}

ANTRA. Associação Nacional de Travestis e Transexuais. Dossiê dos assassinatos e da violência contra pessoas trans em 2019. Rio de Janeiro, 2019. Disponível em: https://antrabrasil.files.wordpress.com/2020/01/dossic3aa-dos-assassinatos-e-daviolc3aanciacontra-pessoas-trans-em-2019.pdf.

ANTRA. Associação Nacional de Travestis e Transexuais. Boletim no 05/2020: assassinatos contra travestis e transexuais brasileiras em 2020. Rio de Janeiro, 2020. Disponível em: https://antrabrasil.files.wordpress.com/2020/11/boletim-5-2020-assassinatos-antra.pdf.

BENTO, B.; PELÚCIO, L. Despatologização do gênero: a politização das identidades abjetas. Rev. Estud. Fem., Florianópolis, v.20, n.2, p. 559-568, 2012. Disponível em: https://www.scielo.br/pdf/ref/v20n2/v20n2a17.pdf

BRASIL. Ministério da Saúde. Política Nacional de Saúde Integral de Lésbicas, Gays, Bissexuais, Travestis e Transexuais. Brasília, 2013. 


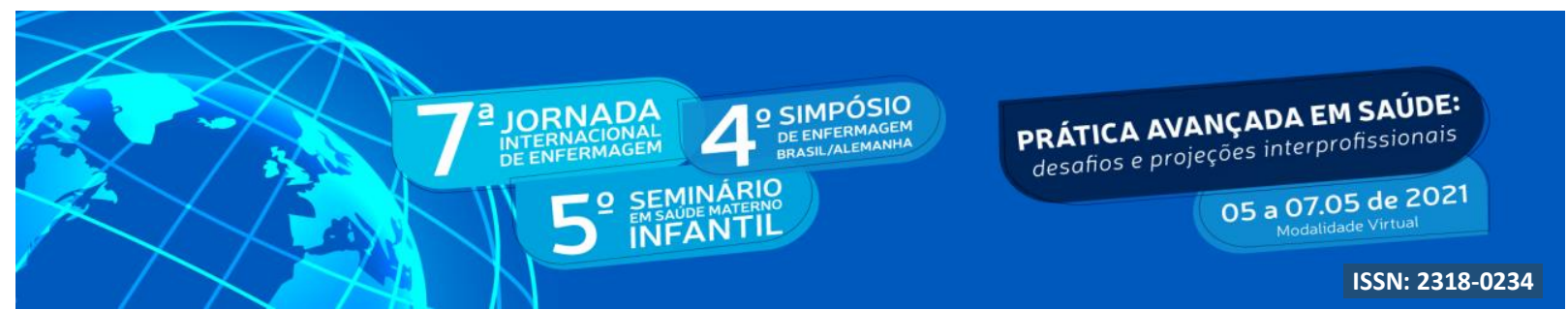

COFEN. Resolução COFEN no 358/ 2009. Sistematização da Assistência de Enfermagem. Disponível em: http://www.cofen.gov.br/resoluo-cofen3582009_4384.html.

FALCON, G.S.; ERDMANN, A.L.; MEIRELLES, B.H.S. A complexidade na educação dos profissionais para o cuidado em saúde. Texto Contexto Enferm. Florianópolis, v. 15. n. 2. p. 343-51, 2006. Disponível em: https://www.scielo.br/pdf/tce/v15n2/a19v15n2.pdf.

FERREIRA, B. de O. et al. Vivências de travestis no acesso ao SUS. Physis, Rio de Janeiro, v. 27, n. 4, 2017. Disponível em: https://www.scielo.br/pdf/physis/v27n4/0103-7331-physis2704-01023.pdf.

MORIN, E. Introdução ao pensamento complexo. $4^{\text {a }}$ ed. Porto Alegre: Sulina; 2011.

MORIN, E. A cabeça bem-feita: repensar a reforma, reformar o pensamento. 17 a ed. Rio de Janeiro (RJ): Bertrand Brasil, 2010.

MENOSSI, M.J.; LIMA, R.A.G. A dor da criança e do adolescente com câncer: dimensões de seu cuidar. Rev Bras Enferm. Brasília, v. 57,n .2, p. 178-82, 2004. Disponível em: https://www.scielo.br/pdf/reben/v57n2/a09v57n2.pdf

OLIVEIRA, V.F.; SILVA, J.D. da, NARVAES, A. Marias, Luisas, Verônicas: o não feminicídio que fere a todas as mulheres. Filosofia e educação: escola, violência e ética / Amarildo Luiz Trevisan, Elisete Medianeira Tomazetti, Noeli Dutra Rossatto (orgs.) - 1.ed Curitiba: Appris, p. 201-212, 2020

PRADO. M; MACHADO. F. Preconceito contra homossexualidades: a hierarquia da invisibilidade. v. 6. São Paulo: Cortez, 2008.

PAIM, J. S. O QUE É SUS. Rio de Janeiro: Editora Fiocruz; 2009.

ROCON, P.; RODRIGUES, A.; ZAMBONI, J.; PEDRINI, M. Dificuldades vividas por pessoas trans no acesso ao Sistema Único de Saúde. Ciênc. Saúde Colet., Rio de Janeiro, v. 21, n.8, p. 2517-26, 2016. Disponível em: https://www.scielo.br/pdf/csc/v21n8/1413-8123- csc-21-082517.pdf.

ROCON, P. C. et al. Acesso à saúde pela população trans no Brasil: nas entrelinhas da revisão integrativa. Trab. edcuc. saúde, Rio de Janeiro, v. 18, n. 1, 2020. Disponível em: https://www.scielo.br/pdf/tes/v18n1/0102-6909-tes-18-1-e0023469.pdf.

SOUZA, M. H. T. et al. Violência e sofrimento social no itinerário de travestis de Santa Maria, Rio Grande do Sul, Brasil. Cad. Saúde Pública, Rio de Janeiro, v. 31, n. 4, p. 767-76, 2015. Disponível em: https://www.scielo.br/pdf/csp/v31n4/0102-311X-csp-31-04-00767.pdf.

SILVA, M.M.; MOREIRA, M.C. Challenges of systematization of nursing care in palliative care in cancer: a complexity perspective. Rev Eletrônica Enferm. v.12, n.3. p.483-90, 2010. Disponível em: http://www.fen.ufg.br/fen_revista/v12/n3/v12n3a10.htm. 